Open Access

\title{
Heterotaxy Syndrome
}

\author{
Soo-Jin Kim, MD \\ Division of Pediatric Cardiology, Department of Pediatrics, Konkuk University Hospital, Seoul, Korea
}

\begin{abstract}
Heterotaxy is defined as an abnormality where the internal thoraco-abdominal organs demonstrate abnormal arrangement across the left-right axis of the body. This broad term includes patients with a wide variety of very complex cardiac lesions. Patients with heterotaxy can be stratified into the subsets of asplenia syndrome and polysplenia syndrome, or the subsets of heterotaxy with isomerism of the right atrial appendages and heterotaxy with isomerism of the left atrial appendages. Treatment of patients with isomerism is determined by the nature and severity of the associated cardiac and extracardiac lesions. Most cardiac operations for patients with isomerism are palliative in nature, since normal anatomy is rarely achieved and mortality rates remain high for patients with heterotaxy syndrome. Patients with left isomerism in general have less severe cardiac malformations than those with right isomerism and, hence, more chance of biventricular repair. For almost all patients with right isomerism, and for many with left isomerism, biventricular repair will not be feasible, and all palliative protocols are then staging procedures prior to a Fontan-type repair. Recent advances in medical management, and improvements in surgical techniques have resulted in improved survival for these patients, and the surgical outcomes are comparable to those with Fontan circulation irrespective of the presence or absence of heterotaxy. (Korean Circ J 2011;41:227-232)
\end{abstract}

KEY WORDS: Heterotaxy; Isomerism.

\section{Introduction}

It has long been recognized that many of the most complex cardiac lesions are found in the hearts of patients with unusual arrangement of abdominal organs, or so-called heterotaxy. It is also well recognized that one of the dominant features of such patients is either absence of the spleen, or presence of multiple spleens on each side of the dorsal mesogastrium. ${ }^{1)}$

\section{Definitions}

\section{Heterotaxy and heterotaxy syndrome}

The word heterotaxy is derived from the Greek: heterosmeaning other than, and taxis- meaning arrangement. ${ }^{2)}$ Hete-

Correspondence: Soo-Jin Kim, MD, Department of Pediatrics, Cardiovascular Center, Konkuk University Hospital, 4-12 Hwayang-dong, Gwangjin-gu, Seoul 143-729, Korea

Tel: 82-2-2030-7678, Fax: 82-2-2030-7748

E-mail: ksoojn@yahoo.co.kr

- The author has no financial conflicts of interest.

$@$ This is an Open Access article distributed under the terms of the Creative Commons Attribution Non-Commercial License (http://creativecommons.org/licenses/by-nc/3.0) which permits unrestricted non-commercial use, distribution, and reproduction in any medium, provided the original work is properly cited. rotaxy, therefore, literally means a pattern of anatomical organization of the thoracic and the abdominal organs which is not the expected usual or normal arrangement; it is also known as "situs solitus".

In the normal body, the internal organs are arranged in different patterns on the right and left sides, and are not mirror images of each other. Hence, if asymmetry of the thoracic and abdominal organs is the usual or normal situation, the syndrome of visceral heterotaxy includes patients with an unusual degree of symmetry of some of the thoracic and abdominal organs, and the atrial appendages within the heart (Fig. 1). This broad term includes patients with a wide variety of very complex cardiac lesions. Patients with heterotaxy can be stratified into the subsets of asplenia syndrome and polysplenia syndrome, or the subsets of heterotaxy with isomerism of the right atrial appendages and heterotaxy with isomerism of the left atrial appendages.

The Nomenclature Working Group ${ }^{1)}$ offers the following definition for the term "heterotaxy": "Heterotaxy" is synonymous with 'visceral heterotaxy' and 'heterotaxy syndrome. Heterotaxy is defined as an abnormality where the internal thoraco-abdominal organs demonstrate abnormal arrangement across the left-right axis of the body. 


\section{Isomerism}

The word isomerism is also derived from the Greek: isomeaning equal and meros-meaning part. Isomerism refers to structures that are themselves mirror-imaged. When used in the area of the congenitally malformed heart, the term "isomerism" has become the conventional description for the situation in which morphologically right structures or morphologically left structures are found on both sides of the body in the same individual.

The Nomenclature Working Group offers the following definition for the term "isomerism": Isomerism in the context of the congenitally malformed heart is defined as a situation where some paired structures on opposite sides of the leftright axis of the body are, in morphologic terms, symmetrical mirror images of each other.

\section{Left Isomerism}

Left isomerism in the context of the congenitally malformed heart is defined as a subset of heterotaxy where some paired structures on opposite sides of the left-right axis of the body are symmetrical mirror images of each other, and have the morphology of the normal left-sided structures. Those patients with isomeric left atrial appendages frequently have bilaterally bilobed lungs, each with a long bronchus, and multiple spleens.

In many cases of isomeric left appendages, patients have pulmonary veins connecting to both the atrial chambers as if both atriums were morphologically left atriums. The symmetry, however, is far from complete.

\section{Right Isomerism}

Right isomerism in the context of the congenitally malformed heart is defined as a subset of heterotaxy where some paired structures on opposite sides of the left-right axis of the body are symmetrical mirror images of each other, and have the morphology of the normal right-sided structures. Those patients with isomeric right atrial appendages frequently have bilaterally trilobed lungs, each with a short bronchus, and absence of the spleen. Once again, however, examples exist where the sidedness of the atrial appendages is not concordant with the sidedness of the lungs or spleen.

\section{Situs ambiguous}

Situs Ambiguus is defined as an abnormality in which there are components of situs solitus and situs inversus in the same person. Situs ambiguus, therefore, can be considered to be present when the thoracic and abdominal organs are positioned in such a way with respect to each other as to be not clearly lateralised and thus have neither the usual, or normal, nor the mirror-imaged arrangements. All patients with heterotaxy should also be considered to have "situs ambiguus" and all patients with "situs ambiguus" also have heterotaxy syndrome.

\section{Incidence and etiology}

It is difficult to calculate precisely the incidence of isomerism due to the potential underestimation of the incidence and prevalence. It seems likely that most cases of right isomerism are recognized in infancy because of the presence of severe forms of cyanotic heart disease. Failure to recognize left isomerism is more likely because of the wider range of associated heart diseases, including mild forms that may not even warrant surgical intervention.

Interestingly, Asians show a higher prevalence of heterotaxy syndrome (32\%) compared to Westerners. ${ }^{3)}$ Therefore, among the patients who underwent a Fontan operation in Korea, those with heterotaxy syndrome account for a greater proportion compared to those in Western nations.

There seems to be no single etiological factor responsible for the development of abnormal lateralization and isomerism. Evidence from human studies and animal models suggests causal heterogeneity. Chromosomal anomalies are only rarely associated with visceral heterotaxy.

\section{Clinical findings}

The prognosis of patients with complex cardiac lesions and heterotaxy is poor. The 1-year mortality is $>85 \%$ for patients with asplenia and $>50 \%$ for patients with polysplenia. ${ }^{4)}$

Isomerism is a fundamental disorder of lateralization, and is often associated with important extracardiac anomalies. A careful evaluation of all systems is mandatory prior to referral for cardiac surgery. In general, the intracardiac structures and connections can be accurately defined by experienced cardiologists.

Almost without an exception, infants with right isomerism have obstruction of the pulmonary outflow tract, as well as common mixing situations, and pulmonary atresia is present in two-fifths of cases. ${ }^{5)}$ While cyanosis is by far the most common presentation, occasionally infants with right isomerism present with severe respiratory distress and cyanosis resulting from an obstructed anomalous pulmonary venous connection. This is most common when the anomalous venous connection is supracardiac in nature. Patients with right isomerism may occasionally present with serious extracardiac anomalies ${ }^{677}$ or, more rarely, with a murmur originating from the pulmonary outflow tract when pulmonary stenosis is mild and cyanosis has gone unrecognized. In these situations, physical examination may provide clues to the presence of an abnormal arrangement of the organs, such as a right-sided cardiac apex or a midline liver.

The clinical findings in patients with left isomerism are nonspecific and will reflect the lesions associated with left isomerism. In contrast to right isomerism, the heart disease may be relatively mild. Indeed, we have observed the presence of isomerism of the left atrial appendages in association with interrupted inferior caval vein and no other cardiac or vascular 
abnormalities. Such patients may never be diagnosed as having isomerism unless extracardiac anomalies, such as biliary atresia or intestinal malrotation, draw attention to the abnormal arrangement of the abdominal organs.

In a review of all patients diagnosed with isomeric left atrial appendages, ${ }^{2)}$ two-thirds had simpler forms of cardiac disease that were potentially suitable for biventricular repair. The remaining patients had complex cyanotic heart disease, frequently associated with a univentricular atrioventricular connection. Some infants with left isomerism present with cyanosis because of the combination of common mixing situation and obstruction of the pulmonary outflow tract. As for left isomerism, many infants with complex disease and isomeric left appendages present with cardiac failure owing to left-to-right shunting without pulmonary obstruction, and frequently present with obstruction of the left ventricular outflow tract.

\section{Extracardiac abnormalities and other associated problems}

There is a high incidence of abnormalities of the renal tract, especially biliary atresia, in isomerism. Routine abdominal ultrasound, with a focus on the biliary tree, is warranted even in the absence of jaundice in infants with left isomerism.

Persistent vomiting in the neonatal period should raise suspicion of a upper gastrointestinal obstruction owing to duodenal atresia or compression. Also, late intestinal obstruction might be caused by gastrointestinal malrotation or gastric volvulus.

The state of the spleen should be established in all patients. When congenital absence of the spleen is diagnosed, there is a lifelong risk of overwhelming infection. When septicemia develops in the asplenic patient with congenital cardiac disease, the clinical course is often fulminant. ${ }^{899)}$

Waldma et al. ${ }^{10)}$ showed a greater frequency of fulminating and fatal septicemia produced by encapsulated bacteria in patients with asplenia syndrome compared with appropriate controls. It is generally recommended that some form of prophylaxis be given for congenitally asplenic patients. Klebsiella and Escherichia coli are the principle pathogens in patients younger than 6 months of age, whereas Streptococcus pneumoniae (pneumococcus) and Haemophilus influenzae are the predominant pathogens after 6 months. The Report of the Committee on Infectious Diseases of the American Academy of Pediatrics recommendations include continuous antibiotic prophylaxis in infants, children, and adults with asplenia syndrome. For antimicrobial prophylaxis, oral penicillin $\mathrm{V}(125 \mathrm{mg}$, twice a day, for children younger than 5 years of age and $250 \mathrm{mg}$, twice a day, for children 5 years of age and older) is recommended. Some experts recommend amoxicillin (20 mg/kg per day).

H. influenzae vaccine (Hib Vax), and hepatitis B vaccine should be given as routinely recommended in infancy. Pneumo- coccal conjugate vaccine is recommended for routine administration as a four-dose series for all children 23 months and younger (PCV7), and a dose of PS23 is recommended to be given at 24 months and an additional dose 3 to 5 years after the first dose. Quadrivalent meningococcal vaccine is recommended for optimal effect at 2 years of age or older. Routine use of yearly influenza vaccine is also recommended in debilitated cardiac patients.

\section{The electrocardiogram and abnormalities of cardiac rhythm}

In some instances of right isomerism, right- and left-sided atrial origin of the $\mathrm{P}$ wave is present at different times in the same patient, reflecting activity of bilateral sinus nodes. ${ }^{11-13)}$ In left isomerism, true sinus rhythm is less common, as might be anticipated from the known hypoplasia of the sinus node in patients with isomeric left appendages. ${ }^{14) 15)}$ In many patients, progressive slowing of rate has been noted with advanced age, leading to the need for placement of a permanent pacemaker. ${ }^{16)}$

Atrioventricular block is exceedingly rare in right isomerism; in contrast, varying degrees of atrioventricular block are common in left isomerism. Overall, complete atrioventricular block is observed in one-tenth of cases with left isomerism.

\section{Treatment}

Treatment of patients with isomerism should be determined by the nature and severity of the associated cardiac and extracardiac lesions. Most cardiac operations for patients with isomerism are palliative in nature, since normal anatomy is rarely achieved. Not surprisingly, then, mortality rates remain high for patients with heterotaxy syndrome. Factors that have historically been associated with increased operative risk include abnormalities of the systemic venous connection, a partial or total anomalous pulmonary venous connection, a common atrioventricular valve that is incompetent, and a morphologic right ventricle supporting the systemic circulation. ${ }^{1718)}$

\section{Biventricular repair}

Patients with left isomerism in general have less severe cardiac malformations than those with right isomerism and, hence, more chance of biventricular repair. Approximately two-thirds of patients with left isomerism have anatomy suitable for biventricular repair. Most commonly, such patients have atrioventricular septal defects, with anomalies of systemic and pulmonary venous return, but with concordant ventriculo-arterial connections. Repair is achieved using standard techniques with appropriate baffling of anomalous venous return. ${ }^{19)}$

After biventricular repair, however, it is common to encounter progressive valvar regurgitation, particularly across the left atrioventricular valve. This often results in the need for reoperation as does recurrent subaortic stenosis, which is more 


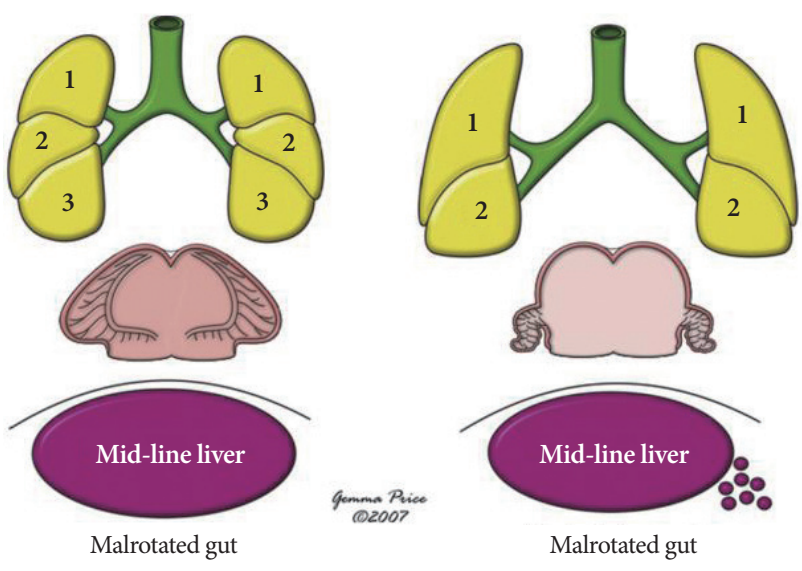

Fig. 1. Typical arrangement of the organs within the body in the setting of visceral heterotaxy. ${ }^{2}$

common in those with left isomerism than in the setting of the usual atrial arrangement.

The anomalies observed in right isomerism are much less amenable to biventricular repair, even when two well-balanced ventricles are present. A few reports of biventricular repair for right isomerism do exist. ${ }^{20-22)}$

\section{Fontan-type procedure}

For almost all patients with right isomerism, and for many with left isomerism, biventricular repair will not be feasible, and all palliative protocols are then staging procedures towards a Fontan-type repair. More complex malformations associated with situs ambiguus, such as common atrium with common-inlet single ventricles or unbalanced ventricles, and complex malformations associated with criss-cross AV relationship and severe straddling AV valve have fewer options for successful surgical correction.

Patients with heterotaxy syndrome usually require palliative surgery in the neonatal period. The palliative procedures are diverse and reflect the highly variable anatomy of this syndrome: a systemic-to-pulmonary shunt, banding of the pulmonary trunk, and a neonatal Norwood approach. When anomalies of a pulmonary venous connection or systemic obstruction are present, special efforts must also be directed toward surgical establishment of appropriate venous connections or relief of systemic obstruction.

After a neonatal palliative procedure, most can opt only for surgical palliation directed toward function as a single ventricle such as with bidirectional cavopulmonary shunts, and, finally, modified Fontan procedures. ${ }^{23)}$ When there is interruption of the inferior caval vein, bidirectional cavopulmonary anastomosis (Kawashima operation) ${ }^{24)}$ will result in all of the systemic venous return being diverted to the lungs except for that returning from the hepatic veins. It has been widely used in patients with left isomerism and is similar to the completion of a fenestrated Fontan circulation. Moreover, these procedures have many late outcomes such as venove-
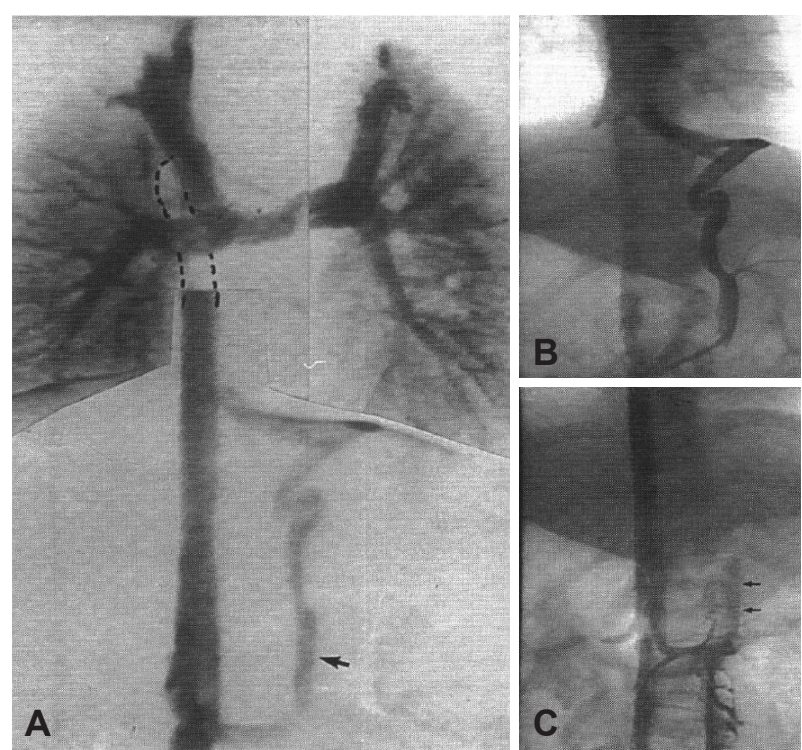

Fig. 2. A venovenous collateral. ${ }^{25)}$

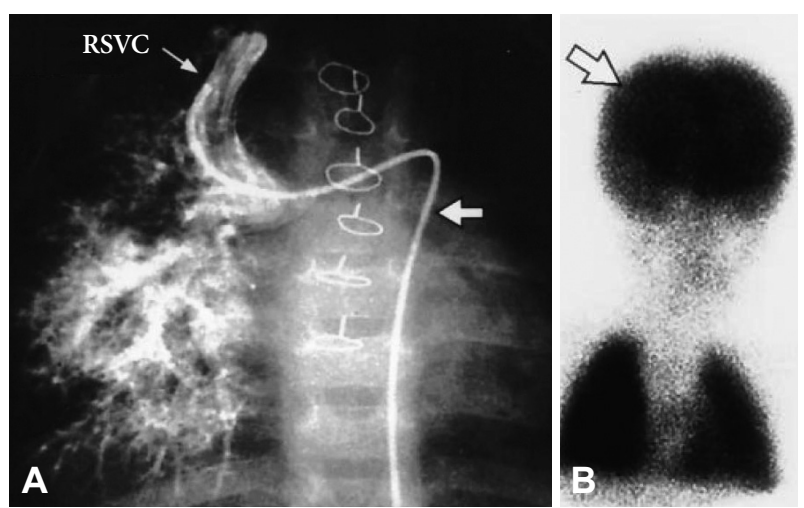

Fig. 3. A: a pulmonary angiogram of a patient who underwent the Kawashima operation showing typical pulmonary arteriovenous fistulas. B: lung perfusion scan results were positive for an intrapulmonary right-to-left shunt. ${ }^{26)}$ RSVC: right superior vena cava.

nous collaterals $\mathrm{s}^{25}$ and the development of pulmonary arteriovenous fistulas (Figs. 2 and 3). ${ }^{2627)}$ Patients with left isomerism seem to be particularly prone to this complication. There is increasing evidence that a hepatic factor may be important in preventing this development. Therefore, a Kawashima operation requires subsequent completion of a Fontan procedure. $^{2829)}$

Initial reports of the outcomes of the modified Fontan operation for heterotaxy syndrome revealed early mortality of $13 \%$ to $80 \%$. These were significantly inferior to those with other single ventricle patterns. ${ }^{4}$ Introduction of the extracardiac conduit technique for construction of a Fontan circuit has a particular benefit for this group, since the need for complex intra-atrial baffles and tunnels is obviated. Also, technical advances and modifications of the Fontan operation have led to markedly improved Fontan procedure results in heterotaxy syndrome (Fig. 4). ${ }^{30311}$

Several reports demonstrated the development of pulmonary arteriovenous fistulas after the Fontan procedure. ${ }^{28)}$ In 


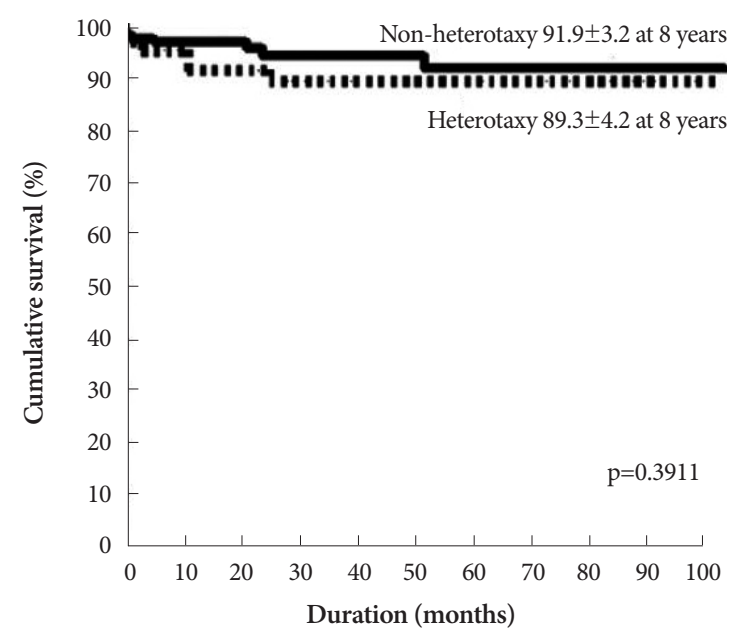

Number at rist

$\begin{array}{llllllllllll}\text { Non-heterotaxy } & 123 & 101 & 83 & 61 & 47 & 42 & 36 & 27 & 17 & 6 & 2\end{array}$ $\begin{array}{llllllllllll}\text { Heterotaxy } & 62 & 53 & 48 & 37 & 29 & 25 & 22 & 18 & 13 & 9 & 2\end{array}$

Fig. 4. Comparison of Kaplan-Meier curves for cumulative survival between patients with and without heterotaxy syndrome. ${ }^{31)}$

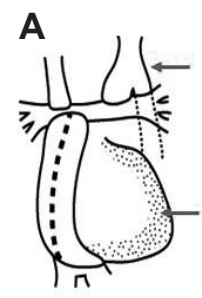

9/F

s/p PAB \& COAplasty (40 d) $\mathrm{s} / \mathrm{p}$ DS \& TCPS (14 m) $\mathrm{s} / \mathrm{p}$ Fontan $(41 \mathrm{~m})$

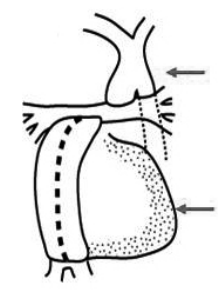

$13 / \mathrm{F}$ $\mathrm{s} / \mathrm{p}$ TCPS $(24 \mathrm{~m})$ $\mathrm{s} / \mathrm{p}$ Fontan $(9 \mathrm{y})$

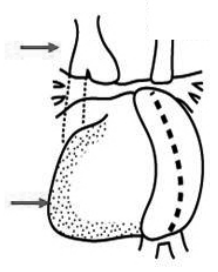

$13 / \mathrm{F}$ s/p RMBT (1 y) s/p TCPS $(2 y)$ s/p Fontan (10 y)

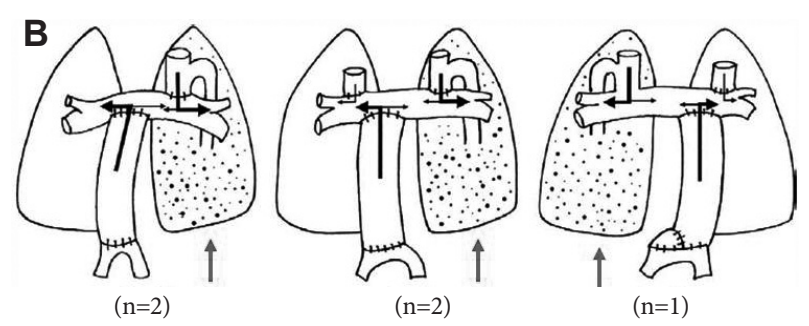

Fig. 5. A: the anatomy of the cardiac mass, the conduit position and the azygous drainage. The main mass of ventricle is on the same side of the azygous drainage and the hepatic conduit position is inevitably on the contralateral side of the azygous drainage. B: the relationship between the conduit position and the azygous drainage site is related to the pattern of persistent pulmonary arteriovenous fistula after Fontan completion. ${ }^{28)}$ PAB: pulmonary artery banding, COA: coactation of aorta, DS: Damus-Kaye-Stansel procedure, TCPS: total cavo-pulmonary shunt.

these cases, it was closely associated with uneven perfusion of hepatic venous drainage and it excluded hepatic blood flow from the pulmonary circulation, similar to the Kawashima operation. These patients had left isomerism with an interrupted inferior vena cava, and had the conduit position on the contralateral side to the superior vena cava with azygous drainage (Fig. 5). It is essential to design the hepatic venous conduit for achieving balanced perfusion to the lungs bilaterally, and sometimes it is not easy to do so. The reason is that the position of the conduit may be inevitably in the contralateral side of the azygous continuation, if the main mass of ventricle is in the same side of the azygous continuation (Fig. 5).

\section{Conclusions}

The heterotaxy syndrome as thus defined is typically associated with complex cardiovascular malformations. Recent advances in medical management, and, in particular, improvements in cardiac surgical skills and techniques occurring around the world, are likely to result in improvements in survival of these patients. Several reports have shown encouraging results, demonstrating that early and late outcomes are comparable between patients with a Fontan circulation irrespective of the presence or absence of heterotaxy. While surgical data suggests improved outcomes, other findings continue to suggest an overall poor prognosis for infants with isomerism when evaluated from the time of birth. This disorder remains one of the greatest challenges for pediatric cardiologists and congenital cardiovascular surgeons.

\section{REFERENCES}

1) Jacobs JP, Anderson RH, Weinberg PM, et al. The nomenclature, definition and classification of cardiac structures in the setting of heterotaxy. Cardiol Young 2007;17(Suppl 2):1-28.

2) Andeson RH, Baker EJ, Penny DJ, Redington AN, Rigby ML, Wernovsky G. Paediatric Cardiology. 3rd ed. Philadelphia: Churchill Livingstone/Elsevier;2010.

3) Kim SJ, Kim WH, Lim HG, Lee JY. Outcome of 200 patients after an extracardiac Fontan procedure. J Thorac Cardiovasc Surg 2008; 136:108-16.

4) Bartz PJ, Driscoll DJ, Dearani JA, et al. Early and late results of the modified fontan operation for heterotaxy syndrome 30 years of experience in 142 patients. $J$ Am Coll Cardiol 2006;48:2301-5.

5) De Tommasi S, Daliento L, Ho SY, Macartney FJ, Anderson RH. Analysis of atrioventricular junction, ventricular mass, and ventriculoarterial junction in 43 specimens with atrial isomerism. Br Heart $J$ 1981;45:236-47.

6) Freedom RM. The asplenia syndrome: a review of significant extracardiac structural abnormalities in 29 necropsied patients. J Pediatr 1972;81:1130-3.

7) Ticho BS, Goldstein AM, Van Praagh R. Extracardiac anomalies in the heterotaxy syndromes with focus on anomalies of midline-associated structures. Am J Cardiol 2000;85:729-34.

8) Dyke MP, Martin RP, Berry PJ. Septicaemia and adrenal haemorrhage in congenital asplenia. Arch Dis Child 1991;66:636-7.

9) Murdoch IA, Anjos RD, Mitchell A. Fatal pneumococcal septicaemia associated with asplenia and isomerism of the right atrial appendages. Br Heart J 1991;65:102-3.

10) Waldman JD, Rosenthal A, Smith AL, Shurin S, Nadas AS. Sepsis and congenital asplenia. J Pediatr 1977; 90:555-9.

11) Blieden LC, Moller JH. Analysis of the P wave in congenital cardiac malformations associated with splenic anomalies. Am Heart J 1973; 85:439-44.

12) Wren C, Macartney FJ, Deanfield JE. Cardiac rhythm in atrial isomerism. Am J Cardiol 1987; 59:1156-8.

13) Momma K, Takao A, Shibata T. Characteristics and natural history of abnormal atrial rhythms in left isomerism. Am J Cardiol 1990;65: 231-6.

14) Ho SY, Seo JW, Brown NA, Cook AC, Fagg NL, Anderson RH. Mor- 
phology of the sinus node in human and mouse hearts with isomerism of the atrial appendages. Br Heart J 1995;74:437-42.

15) Dickinson DF, Wilkinson JL, Anderson KR, Smith A, Ho SY, Anderson RH. The cardiac conduction system in situs ambiguus. Circulation 1979;59:879-85.

16) Frogoudaki A, Sutton R, Gatzoulis MA. Pacing for adult patients with left atrial isomerism: efficacy and technical considerations. Europace 2003;5:189-93.

17) Humes RA, Feldt RH, Porter CJ, Julsrud PR, Puga FJ, Danielson GK. The modified Fontan operation for asplenia and polysplenia syndromes. J Thorac Cardiovasc Surg 1988;96:212-8.

18) Culbertson CB, George BL, Day RW, Laks H, Williams RG. Factors influencing survival of patients with heterotaxy syndrome undergoing the Fontan procedure. J Am Coll Cardiol 1992;20:678-84.

19) Uemura H, Yagihara T, Kawahira Y, Yoshikawa Y. Anatomic biventricular repair by intraatrial and intraventricular re-routing in patients with left isomerism. Cardiol Young 2001;11:12-6.

20) Kawashima Y, Matsuda H, Naito Y, Yagihara T, Kadoba K, Matsuki O. Biventricular repair of cardiac isomerism with common atrioventricular canal with the aid of an endocardial cushion prosthesis. J Thorac Cardiovasc Surg 1993;106:248-53; discussion 253-4.

21) Koh M, Yagihara $T$, Uemura $H$, et al. Biventricular repair for right atrial isomerism. Ann Thorac Surg 2006;81:1808-16; discussion 1816.

22) Lim HG, Bacha EA, Marx GR, et al. Biventricular repair in patients with heterotaxy syndrome. J Thorac Cardiovasc Surg 2009;137:371-9.

23) Allen HD, Driscoll DJ, Shaddy RE, Feltes TF. Moss and Adams'Heart Disease in Infants, Children, and Adolescents. 7th ed. Philadel- phia: Lippincott William \& Wikins;2008.

24) Kawashima Y, Kitamura S, Matsuda H, Shimazaki Y, Nakano S, Hirose H. Total cavopulmonary shunt operation in complex cardiac anomalies: a new operation. J Thorac Cardiovasc Surg 1984;87:74-81.

25) Stümper O, Wright JG, Sadiq M, De Giovanni JV. Late systemic desaturation after total cavopulmonary shunt operations. Br Heart J 1995;74:282-6.

26) Kim SJ, Bae EJ, Cho DJ, et al. Development of pulmonary arteriovenous fistulas after bidirectional cavopulmonary shunt. Ann Thorac Surg 2000;70:1918-22.

27) Srivastava D, Preminger T, Lock JE, et al. Hepatic venous blood and the development of pulmonary arteriovenous malformations in congenital heart disease. Circulation 1995;92:1217-22.

28) Kim SJ, Bae EJ, Lee JY, Lim HG, Lee C, Lee CH. Inclusion of hepatic venous drainage in patients with pulmonary arteriovenous fistulas. Ann Thorac Surg 2009;87:548-53.

29) McElhinney DB, Kreutzer J, Lang P, Mayer JE Jr, del Nido PJ, Lock JE. Incorporation of the hepatic veins into the cavopulmonary circulation in patients with heterotaxy and pulmonary arteriovenous malformations after a Kawashima procedure. Ann Thorac Surg 2005;80: 1597-603.

30) Yun TJ, Al-Radi OO, Adatia I, et al. Contemporary management of right atrial isomerism: effect of evolving therapeutic strategies. $J$ Thorac Cardiovasc Surg 2006;131:1108-13.

31) Kim SJ, Kim WH, Lim HG, Lee CH, Lee JY. Improving results of the Fontan procedure in patients with heterotaxy syndrome. Ann Thorac Surg 2006;82:1245-51. 